\title{
Lessons Learned in Fifteen Years of Evolution of the Linking and MoT Office of a R\&D Public Center
}

\author{
Vega-González Luis Roberto \\ Universidad Nacional Autónoma de México, Mexico \\ Tel: 5622-8602-1135Ｅ-mail: lrvg@servidor.unam.mx
}

Received: Sept. 22, 2015 Accepted: Mar. 4, $2016 \quad$ Published: Mar. 9, 2016

doi:10.5296/csbm.v3i1.8348 URL: http://dx.doi.org/10.5296/csbm.v3i1.8348

\begin{abstract}
In this paper it is proposed that similarly with the evolution and maturation of any organization, the Linking and Management of Technology Office (L \& MoT) of a public R\&D Mexican Centre has been evolved and is in the way to be transformed into a Technology Transfer Office (TTO). Case of fifteen year evolution of the Centro de Ciencias Aplicadas y Desarrollo Tecnológico L \& MoT presents empirical evidence to identify the main phases and actions that have been driving this process along this time. Standard results obtained through the years using the L \& MoT Management of Technology Model (MoT) are presented. Emphasis is placed in a final section with the lessons obtained from non-standard results coming from unsuccessful negotiations and failed link actions between the Center and some external organizations. Experience has shown that not all negotiations are successful but curiously, the best lessons for the personnel of a technology transfer office are probably derived from these problematic cases.
\end{abstract}

Keywords: R\&D Public Organization, Management of Technology, Mexico 


\section{Introduction}

What is the importance of a technology transfer office? University researchers are busy people that in most cases don't want to be involved in commercial and financial negotiations. Rosenberg \& Nelson (1994) indicated that "university researchers generally are almost always insufficiently versed in the particulars of specific product markets to make good decisions about appropriate tradeoffs". Therefore, professionals specialized in economic and administrative matters, with technical knowledge are required to interface the scientific and technical academic R\&D organization's personnel with the enterprises and external organizations requirements. This is the foundation support for the linking and technology transfer organizations and in that sense, the people working in them must have knowledge, experience and competences in understanding the business and the R\&D "languages" to be good interfacing negotiators.

In that vein, a University Technology Transfer Office is the means by which institutions will approach the technology market. According with Arora et al. (2001), cited by Pluvia \& Dominique (2009), the market for technology refers to transactions for the use, diffusion and creation of technology. This includes transactions involving patents and other intellectual property rights (IPR), know-how and patent licensing. It also includes transactions involving knowledge that is not patentable or not patented (e.g., software, or the many non-patented designs and innovations). Patent licensing plays a central role in technology markets.

The research and development knowledge transferred from the university to firms will improve the capability of them to significantly develop or improve their products and manufacturing processes, situation that depends primarily upon the capacity of identification, acquisition, integration and application of knowledge by individuals in the firm and of course of the capability to interact with university research areas (Grant, 1996; Amin \& Cohendet, 2004). Then, technology transfer is a good thing; it is a legitimate part of the University purpose, alongside the core activities of teaching and research, TT does not happen on its own, there needs to be a policy framework, and it takes a long time to demonstrate the success of a technology transfer program (Hockaday, 2009). Today a TTO must be capable to form partnerships with firms, to attract fresh funds to foster a quicker commercial "payoff” to basic research (Cohen et al., 1998; cited by Siegel et al., 2003).

In Mexico the government and several institutions have recently taken a sudden interest in this topic. In June 2009 the Mexican Law on Science and Technology was amended. The aim of the policy changes and incentives was to improve Mexico's innovation dynamics (Chagoya, 2012). Among other things, the law mandated the National Council of Science and Technology to support Mexico's linkage and knowledge transfer units (L \& KTU). These entities were intended to take charge of instigating and executing projects related to technological development and innovation, encouraging the integration of innovation into the manufacturing and service sectors.

A major number of the Mexican L \& KTU's are part of the public universities, and the inspiring vision of its creation was that those entities would be capable of taking 'raw' technologies developed at the universities complete the way from being marketable and 
improve them at least to proof-of-concept stage. Today, Mexican government has fostered programs to develop intellectual property management capabilities in the L \& KTU's, transforming them in Technology Transfer Offices (TTO) as happens in the entire world.

In this paper we present the evolution of an L \& KTU of the UNAM's Applied Sciences and Technological Development Centre which in particular is called Linking and Management of Technology Office (L \& MoT).

\section{The Applied Sciences and Technological Development Centre (CCADET)}

The CCADET is part of the research subsystem of the Universidad Nacional Autónoma de México (UNAM). It was created as Centro de Instrumentos (CI) in 1971 to design and build equipment and didactic material for the schools, faculties, and other research institutes and centers of the UNAM. It also has collaborated with other university entities as the UNAM's Colegio de Ciencias y Humanidades and with other private high schools associated with the UNAM, in its beginning, its activities were focused in the specification establishment, design and development of instruments and laboratory equipment (CCADET, 2014).

Through the Maintenance Units, created during its first ten years of operation, with technical personnel specialized in mechanical, electrical, electronic and informatics, it also realized maintenance and service to the laboratory equipment of other's UNAM's entities. Pretty soon the center acquired good prestige in and outside the UNAM.

Under this work modality it was required the development of hardware parts and subsystems for lab devices as ultra-centrifugal equipment, refrigerators, saline steam chambers, wind chambers, ovens, PH, conductivity and DBO analyzers, and so, used in the Veterinary and Human Medicine, Chemical, Faculties and the Biotechnology, and the Biomedical and Cellular Physiology Institutes, among others. In the center it was also installed a medium size machines workshop where a number of exhibits for the university museums of science and Light were developed. The maintenance and service units were consolidated during the second decade of the institution operations. At that time there were established the Labs of metrology, electronics and mechanic design.

The academic personnel of the center has participated in the human recourses formation teaching at the Engineering, Sciences and Chemistry Faculties and also directing the development of basic technological devices by the students as their final thesis work.

Early 1980's the center authorities began hiring researchers in areas related to physics and mathematics, for that reason its activities diversified going beyond engineering and technological services. Since instrumentation development frequently requires many different types of measurement subsystems related to optics, mechanics, electronics, photonics, new materials and sensors; the new intellectual capital improved the center's potential to develop complex analytical, scientific and industrial instrumentation. Thereby the first research groups focused their work in the fields of optics, acoustics and new materials.

With the continuous incorporation of researchers in 1996, at the middle of their third operations decade, the CI reached the category of a research center according with an 
agreement signed by the Academic University Council of Physics-Mathematics and Engineering.

Because of the formation of other multidisciplinary research groups during the last decade of the 20th Century, in April 2002 the Technical Council of UNAM's Scientific Research issued the agreement to change the center's name from Centro de Instrumentos to Centro de Ciencias Aplicadas y Desarrollo Tecnológico (CCADET).

Doing an intensive knowledge management exercise in 2006, the Internal Council leaded by the center's director, declared that the activities performed by all the academic personnel had to be mainly in the priority knowledge fields of instrumentation, micro and nano technologies, information and communication technologies and the science and technology education. As a result the structure of the center was reorganized and all the academic laboratories were grouped in four departments: Optics, Information and Communication Technologies (TIC), Techno-Sciences, and Micro and Nano-technologies.

With focus in these priority fields, the organization mission today is to perform and integrate multidisciplinary applied research and technological development while at the same time the center's academic personnel must work with their students to form high quality human resources (Ms, PhD). The mandatory idea is that all center's knowledge results will contribute with the solution of relevant society problems. The research results are generally published in Journals while intellectual property titles and certificates are used to protect the inventions and technological results (Saniger, 2013).

Today the academic personnel is composed by about 30 senior research fellows, 9 associated research fellows, 64 academic technicians, 5 post-doctoral scholarships, 150 students and 92 technicians and support personnel. Some researchers still perform basic research; but the general orientation of the investigation and technological activities is to develop projects that must provide integral technological solutions for the technology requirements of external organizations. The center's academic groups are oriented to answer both: the requests from other UNAM's institutions and those coming from external public or private financing organizations too. Certainly this is one of the contributions of CCADET to the solution of the national problems. Therefore, one of the CCADET's activities is to perform reverse engineering and gradual technology improvements projects searching to eliminate importations and to generate technologies that help to improve the competitiveness of external financing profit or nonprofit organizations.

Sometimes technological packages are part of complex innovation processes where firms have the market vision, the timing plan, the technology integration and the implementation strategy (Connelly et al., 2009). In order to obtain governmental money to finance the projects, every year the CCADET signs collaboration agreements with firms that present proposals for technological development projects to different Programs and Funds of The National Council of Science and Technology (CONACYT, 2014).

If the external organization requiring CCADET's collaboration is a public institution, the goal is that the technology developed must improve their operations efficiency in order to 
eliminate technology dependence generating proprietary technology. Then, working through the project management and the technology development projects, the center participates in the innovation projects of the associated organizations (Davenport, 1996).

The projects developed during the last decade have shown that the center's application priority areas are Education, Health, Energy and Environment.

\section{The Linking and Management of Technology Office (L \& MoT)}

Since the Center's origin there was an intuitive idea among the academic personnel and their authorities about the need of realizing linking actions with external organizations and to pursue technology management projects. This was stated as an objective to perform in the operative regulations of the institution. In the early years of the center those actions were directed specifically to other UNAM entities. A second working area was the realization of feasibility studies for the industrial production of scientific and analytical instrumentation equipment. In the Center's creation objectives it was also expressed the requirement for the promotion of patents to protect the UNAM's property. Today, forty five years later, the center's objectives have been expanded to realize linking actions with other society sectors and to transfer the technology developed by the CCADET to the productive and academic sectors, both intending to contribute with the national technological innovation and to improve the country's science, technology and education. Since 1971 to 1999 the linking actions were directly done by the academic personnel performing the projects and the authorities, who signed the agreements, because there was no office in charge of the coordination of those activities.

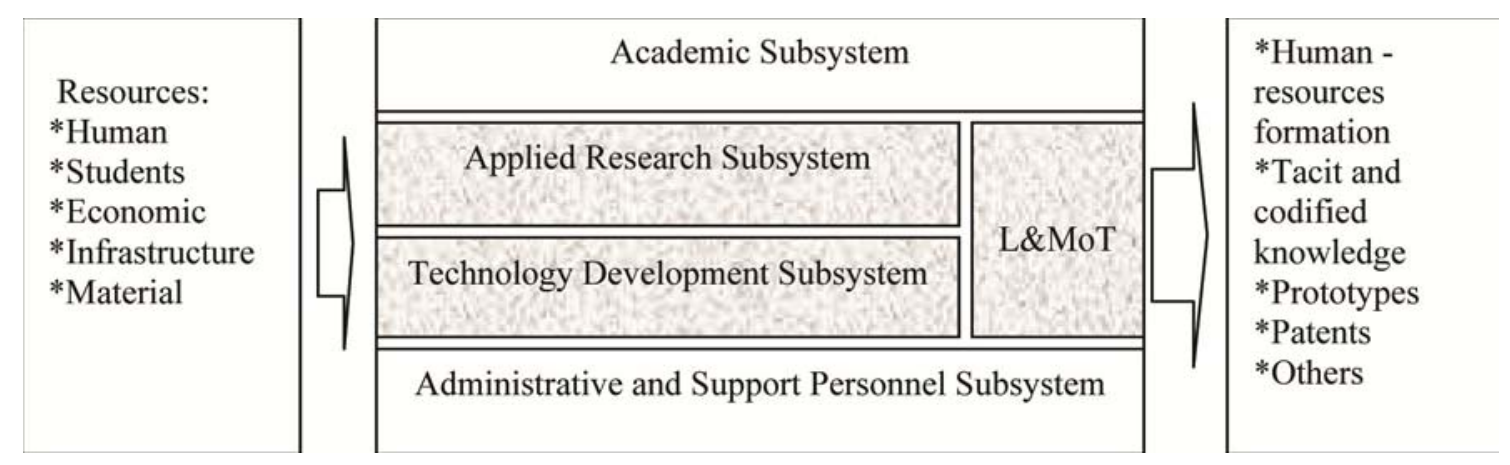

Figure 1. The L \& MoT organization subsystem

As can be seen in Figure 1, the L \& MoT subsystem is a part of the general operations system of the CCADET, The Center has following subsystems: academic, research, technology development, administration, quartermaster and support. The inputs are all the resources required to perform their normal R\&D and teaching activities and also the projects demanded from external organizations. The output is knowledge in many different embodied and non-embodied forms produced by the center to satisfy the external society clients. 
Franzoni (2007) describes that during late 1980's it was occurring an interesting phenomenon in the international context, particularly in different universities of the United States of North America, many Technology Transfer Offices (TTO's) were created. At that time something similar occurred at the UNAM, it created the Centro para la Innovación Tecnológica as a centralized TTO devoted to attend the requirements of technology management and linking of all the university dependences. This dependence disappeared in 1997 and was transformed into a new organism called Coordinación de Vinculación which also disappeared in 2001.

\subsection{Evolution of the L \& MoT Office into a TTO}

The CCADET's Linking and Management of Technology Office (L \& MoT), (in Spanish: Coordinación de Vinculación y Gestión Tecnológica) initiated its operations in 1999 as an external financed projects administration office. Their main objectives were to transfer, disseminate, and disclose to the industrial society and other sectors related with the instrumentation the scientific and technologic knowledge generated by the research and development laboratories.

Initially it acted as a kind of public relations office with special working emphasis in the big projects contracted that will require intense relations and communications between the center and the external organizations and the administrative and legal offices of both parties. The head of the L \& MoT reported to the CCADET's director and its activity made the researchers and academic personnel were free of economic, legal and administrative project matters and nightmares. From 1999 up to 2004 the main activities of the management of technology and linking office were project administration and the public and legal relations with the external clients of the center. The L \& MoT just had capabilities such as linking with external organizations, opportunities identification, promotion, submission of technical-economic proposal presentations and commercial negotiations.

According with the OECD (2003), in the early 2000's, most countries have enacted the American Bayh-Dole Act legislation which grants universities the rights over their own intellectual property (IP). In that regard, the Universidad Nacional Autónoma de México also reacted to this international legal stream and claimed the IP rights of the technology developed by their entities as its property. By 2004 the CCADET's L \& MoT office created its Intellectual Property Unit (IPU). Pretty soon its personnel developed capabilities for writing and filing patents and other intellectual property titles, intellectual protection strategy for the center's results, and licensing strategies required for negotiation of technology transfer contracts. Since then, several patent titles and applications have been filed and intense work have been done to obtain the registers of the center's copyrights and software rights. As noted by Siegel et al. (2003), cited by Bart et al. (2007), this is a first step towards the professionalization of a TTO.

Through the following years some technology licensee and technology transfer contracts were signed between the CCADET and external firms, therefore the L \& MoT office evolved as the CCADET's Technology Transfer Office (OTT); nevertheless, since technology transfer is an interactive and complex process between organizations, it is not an easy task in any part of the world (Zhao \& Reisman, 1992). With the sum of all its capabilities, including diffusion 


\section{Macrothink}

Case Studies in Business and Management

ISSN 2333-3324

2016, Vol. 3, No. 1

surveillance and R\&D+I projects evaluation, the L \& MoT is actually considered as a full Technology Transfer Office.

Even that according with Bradley et al. (2013), a linear model is not sufficient to account with the complexities of the technology transfer process, it is a good approach; therefore, the L \& MoT office has developed a four phase's technology management model, as shown in Figure 2

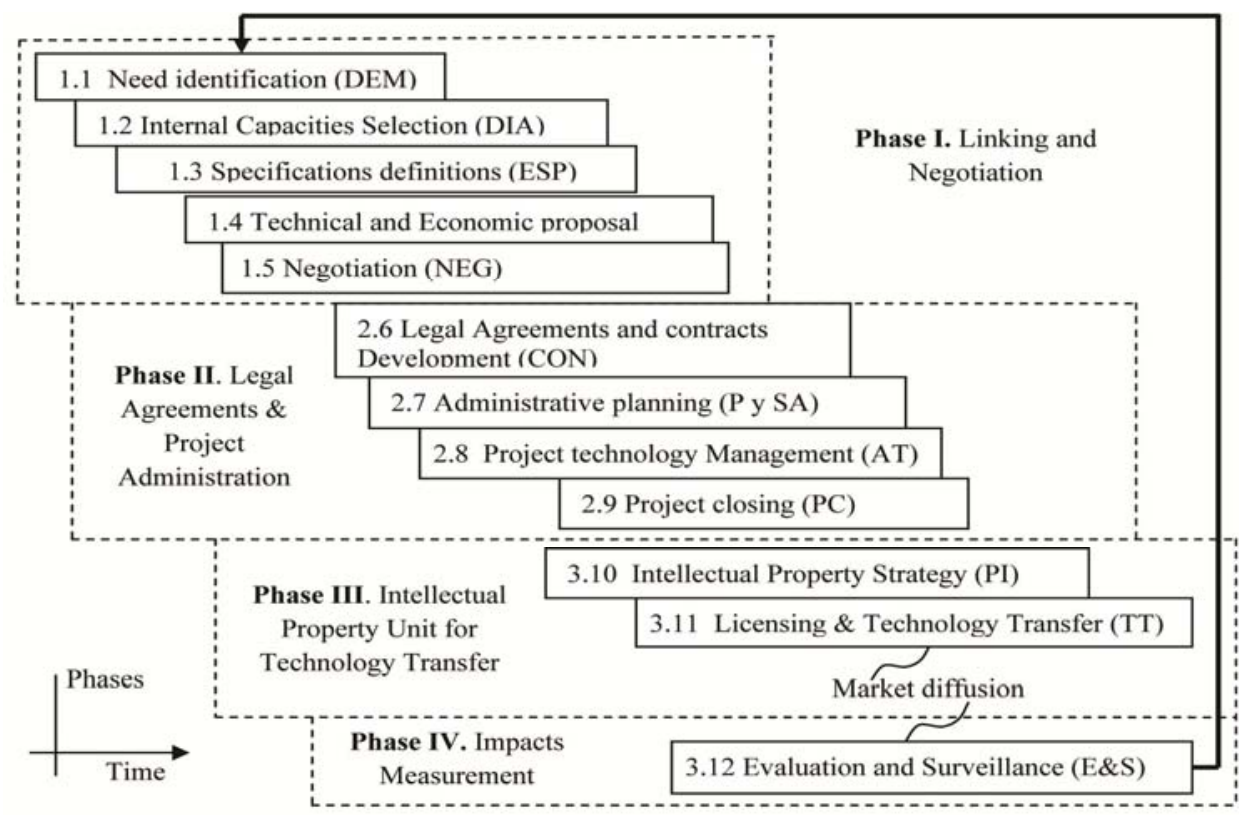

Figure 2. Technology management model of the CCADET

\subsection{Standard Results of the L \& MoT Office Operations}

Using its technology management operations model, by 2012 after 13 years of operations the L \& MoT office had developed, negotiated and signed a number of legal instruments and agreements as can be seen in Figure 3.

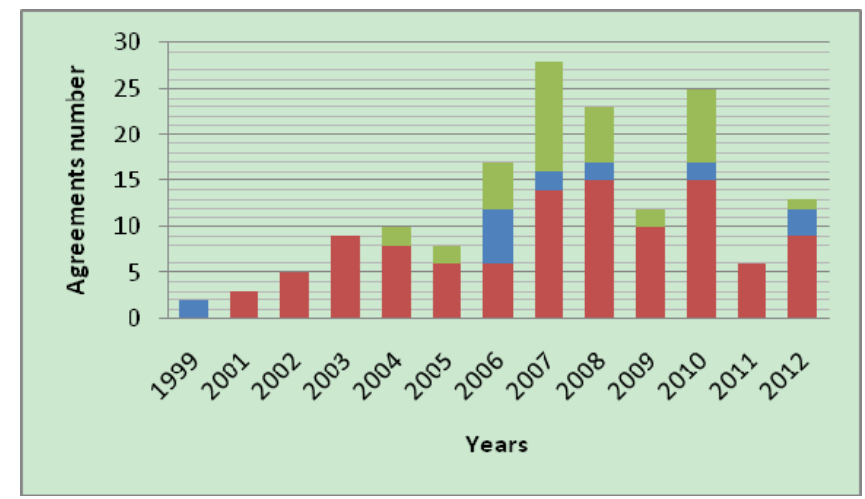

Figure 3. Legal agreements signed by year 


\section{Macrothink}

Case Studies in Business and Management

ISSN 2333-3324

2016, Vol. 3, No. 1

The externally funded projects have been performed for public and private national firms, international private firms and governmental development entities, which are public nonprofit organizations, as shown in Figure 4.

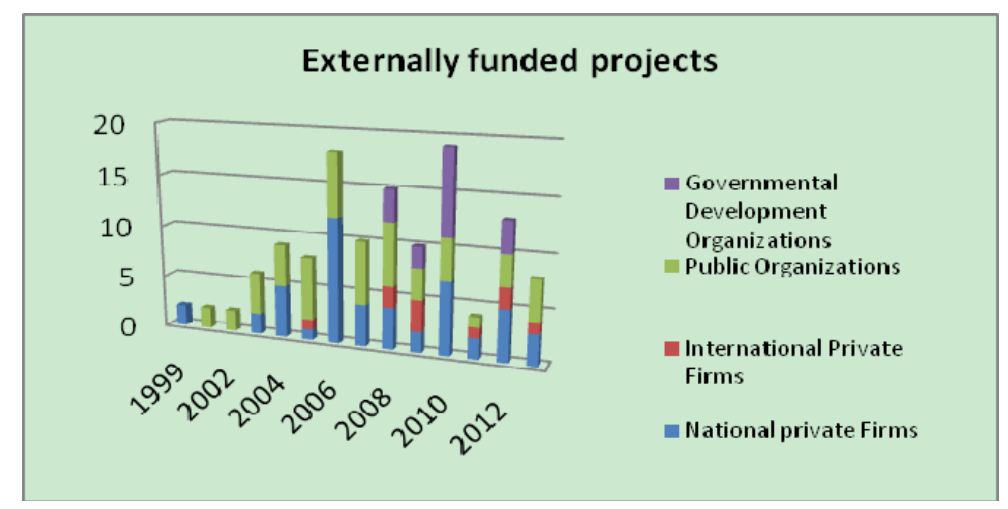

Figure 4. Externally funded projects by organization type

Table 1. Legal agreements signed and extraordinary incomes by projects

\begin{tabular}{|l|l|l|}
\hline Legal Instruments (2001-2012) & Total & Incomes (Mexican Pesos) \\
\hline General and specific collaboration agreements & 106 & $\$ 90,615,034.00$ \\
\hline Project Scope Modification Agreements & 4 & $\$ 0.00$ \\
\hline Technology transfer & 17 & $\$ 3,155,522.00$ \\
\hline Technology Services and development & 38 & $\$ 1,946,939.00$ \\
\hline Letters of Intent (Memorandum of Understanding) & 18 & $\$ 2,355,000.00$ \\
\hline Inter institutional Collaboration Bases & 15 & $\$ 4,919,000.00$ \\
\hline Donation, Co-edition, and other Contracts & 20 & $\$ 12,518,000.00$ \\
\hline TOTAL & 216 & $\$ 115,509,496$ \\
\hline
\end{tabular}

Table 1 shows the collaboration agreements signed and the amounts of the funds obtained from them.

In Figure 5 we can see a phenomenon of political seasonality in the projects externally funded. Notably the years with less projects incomes were 2006 and 2012, when in the country there were political elections for President. 


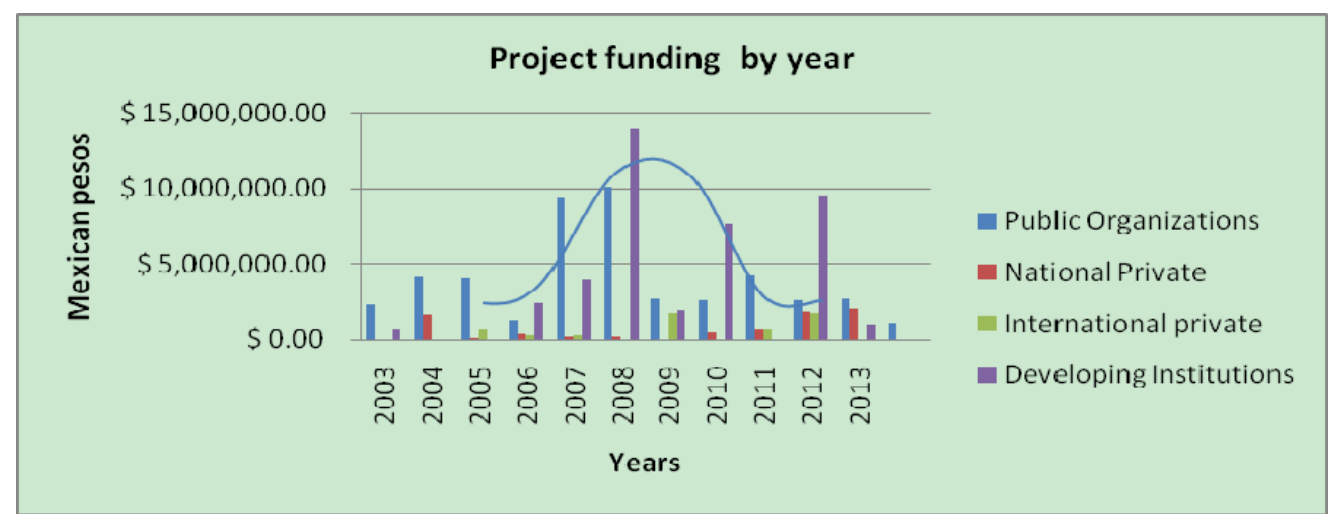

Figure 5. Funding of the projects developed for external organizations

Figure 6 shows the type of technology delivered in the projects contracted by the CCADET with external organizations in the years studied. The CCADET was mainly contracted to realize research and/or for consulting services (43\%), in second place the groups of the Education in Science and Technology department delivered didactic materials and prototypes (18\%), the third strength of the CCADET corresponded to the Information Technologies department who delivered software systems for specific purposes (17\%). The center was also contracted to perform specialized services and some manufacturing (14\%), and finally in only $8 \%$ of the collaboration agreements signed by the center there were software embedded in integrated prototypes and apparatus.

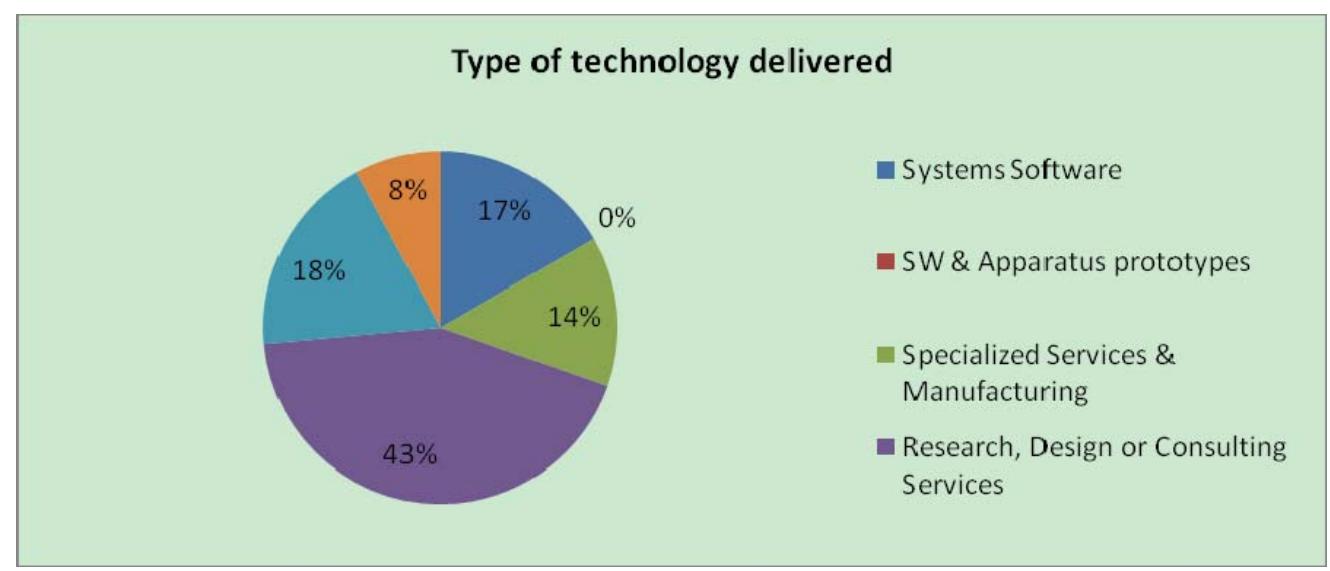

Figure 6. Type of technology delivered to the externally financed projects.

\section{The Intellectual Property Unit of the CCADET's L \& MoT Office}

The Intellectual Property Unit (IPU) was created in 2004 with the original activities for managing the Center's personnel author rights, computer programs registers, ISBN and ISSN numbers, and trademarks. Starting 2008 the responsibility of the IPU expanded to patents, industrial designs and industrial models. Figure 7 shows the results obtained by the IPU. 


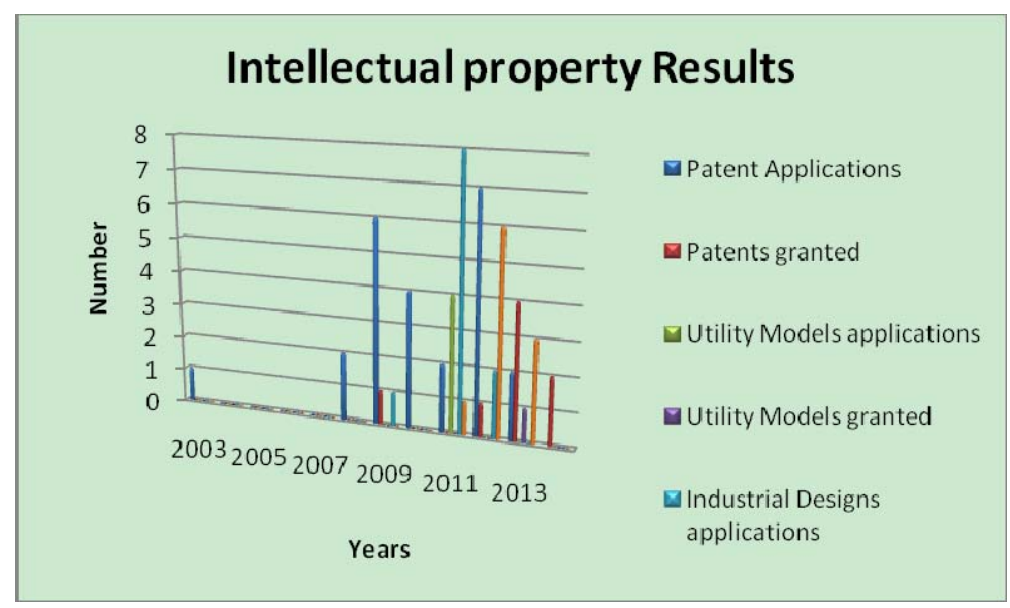

Figure 7. CCADET’s Intellectual property unit results

The main IPU results up to date are: 10 patent titles obtained, 16 patent applications, 4 PCT patent applications, 4 patent documents in writing, 4 utility models applications, 4 industrial designs titles, 11 industrial designs applications, 12 trademarks, 62 copyrights, 19 software rights, 13 ISBN numbers and 2 ISSN numbers.

\section{L \& MoT Non-Standard Results and Lessons Learned}

During the 15 operation years of the L \& MoT office there have been special situations that brought unsuccessful negotiation of some projects. In next section a number of cases are presented.

\subsection{Complex Donation Contracts}

Case of analytical reagents donation: The hospital "20 de Noviembre" who depends of the Federal Government Health Secretary offered to the center the donation of a lot of analytical reagents in 2005. It was required to develop two different agreements in four years to clear up all the legal complications coming from the big special dangerous substances storage room required and the monetary amount involved ( $\sim 500,000.00$ USD). People have the common idea that a donation of parts, materials, equipment or devices among others must be an easy procedure lasting just some days or months.

The lesson obtained from this case, confirmed later by the handling of other similar cases, is that because the tremendous amounts of bureaucracy and the problems to match the legislation of the counterpart's, in the facts, the handling of this kind of contracts could be an enormous nightmare. Other UNAM's entities have had donation contracts in which it has been obvious that the donating organization use them as a strategy to clean "dirty files" when there are no invoices to probe the origin of the goods or the money spent. Sometimes a donation is also a procedure to get rid of obsolete or inoperable equipment.

\subsection{Technology Development Difficulties}


The "Maestro Tuercas" was a project for the development of didactic material consisting in laboratory panels for teaching electrical, pneumatic refrigeration and air control systems to technician students. The project was co-financed by Harry Mazal Co., and the Consejo Nacional de Ciencia y Tecnología (CONACYT), when it began, was proposed for two years development and $\sim \$ 100,000.00$ USD financing. The final project informs accountability demonstrated that the project exceeded the initial projected resources requirements. It required five years to be finished, twice the academic group time expected and the center spent more than three times the money initially proposed.

Lesson learned: Good procedures for preparing economic proposals making good estimations of the economic and the intellectual capital resources required for the development of a project, need to be learned and reviewed continuously.

\subsection{Complications to Adjust the International Laws Agreement Terms}

Between 2005 and 2008, the Center signed more than ten agreements with the Instituto Latinoamericano de la Comunicación Educativa, (ILCE) in order to develop materials and pedagogic units for educational projects. In all the cases the negotiation of the legal instruments was very difficult because in México the ILCE has the legal status of international institution that must be treated nearly as an external country embassy according with the international laws. Furthermore, there were some difficulties to get a fair agreement in the intellectual property clauses.

Lesson learned: international affairs require special attention and it is required to spend extra time to clear up the legal terms, sometimes it will be required to have some international attorneys.

\subsection{Initial Project Specifications Misunderstood}

In 2002 and 2004 with funds coming from CONACYT the center signed two different agreements with the Instituto Nacional de Cardiología to develop a single and multiple cardiac bio prostheses tester. At the end of the projects there were difficulties to close them because of differences in the expectations and the perspectives that clients and the academic groups had about the initial specifications and the final prototypes performance.

Lesson learned: it is extremely important to get an initial technical specification truly explicit, clearly understood and signed by both parties.

\subsection{Paradoxical Results in Projects Negotiations}

In 2008 CCADET began negotiations with the Instituto de Ciencia y Tecnología del Distrito Federal (ICYTDF) for a consultancy project in the field of design, installation, and start up support for a digital mammography equipment network to be installed in the sixteen political delegations of Mexico City. During the negotiations and without previous notice the engineering supervision project was awarded by the Health Secretary to some diagnostics equipment supply company. Probably in compensation, the Center received a contract to develop five R\&D projects. Among them there was financing to develop new diagnostics systems for mammary cancer (MaCa-Dx). Paradoxically those R\&D proposals were presented 
as optional in the initial proposal for the engineering supervision project. The end of the project was proposed by the final quarter of 2010 and it was necessary to sign a modification agreement to extend the ending date. At the beginning of the project there were no administrative manual for the economic resources management, therefore the economic resources were managed according with UNAM's standard procedures. The result was that there were some minor economic administrative differences related to the use of the funds that needed to be cleared up to sign the ending minute.

Lessons learned: it is mandatory the continuous surveillance of the required projects using marketing intelligence personnel to be aware of possible changes in the evaluation criteria to make decisions and it is advisable to fully clarify since the beginning of the project the procedures required by the financing entity for the administration of the economic funds.

\subsection{Unexplained Change of Mind of a Customer}

In 2011 the CCADET's Intelligent Systems academic group negotiated in conjunction with the Systems group of the UNAM's Science's Faculty a project valued $\sim \$ 400,000.00$ USD to develop a communications failure Expert System with a subsidiary company (confidential name) of the biggest telecommunications group in Mexico. Surprisingly the same week the project agreement was signed and the payment in advance check was issued, with no explanation at all, the company cancelled the contract and asked their money back. Trying to gain some time, the purchase of some materials and some contracting interviews had already been done.

Lesson learned: never begin the purchase of materials and the hiring of people until the agreement has been signed, the money has been received and the startup project meeting letter has been signed. The last alternative is to use a penalties clause, not always recommended for the negotiations success.

\subsection{Hundreds of Unproductive Negotiation Hours}

Along its 15 operations years, the L \& MoT personnel has supported the academic groups of the center with a big amount of difficult negotiations for projects going in the phase 1 of the model, spending many useless working hours that never ends in the signature of an agreement or letter of intent. Naturally, the time spent in negotiations cannot be reported, is completely unproductive and it cannot be counted in the results table. The statistics indicate that from fifteen project possibilities that require multiple negotiation hours, it is only possible to sign between one or two projects.

Lesson learned: since time is a scarce resource we must use it properly and efficiently; that means that it is required to work on a program of meetings and only call for extra meetings when it is strictly necessary and avoid the non-necessary meetings when possible. It is essential to use efficient negotiation techniques to close contracts.

\subsection{Learning by Interacting in International Private-Public Cooperation}

In 2007, the USA subsidiary of Total Petrochemicals Inc. (TOTAL), a French multinational private firm with core competences in the petrochemical field, contracted the group of process 
engineering of the CCADET to develop a prototype of an automatic molding press (AMP) system. The firm was willing to sign a collaborative contract for technology development with CCADET in a balanced relationship in which the Mexican R\&D Center acted as the technology supplier (Vega-González et al., 2012).

Since the negotiations were developed between an international private company and a public Mexican university, there were several problems with the legal terms and clauses before the parts were able to sign the collaboration contract to develop the AMP.

Other complications were the commercial terms to be used in the agreement, for example, it was necessary to use the term 'receipt' instead of 'invoice' and to include an explicit clause indicating that the AMP system would be delivered FOB Mexico City. The main complication came when the UNAM's General Lawyer's Office required the power of attorney of the TOTAL officer entitled to sign the contract. Since this is not a common requirement in US commercial contracts the only way to overcome this was to present a Certificate of the Secretary for the Vice-President of Technology who signed the contract. It took several months to clear up all legal differences and the commercial terms to sign the contract. The equipment was delivered in 2008 and project ends successfully.

Lesson learned: when performing international projects it is necessary to be aware that surely there will be differences in the laws and regulations that probably will consume extra time to get collaboration agreements signed.

\subsection{Management of Technology for High Level Cooperation Agreements}

Since 2008 and during 2011 and 2012 some research fellows from the Applied Biophysics and Medical Physics academic group of the Center were participating in different techno-scientific workshops related to medical sickness problems and the measurement problems physicians face regarding physical variables for diagnostics and treatment of chronic degenerative sicknesses as urethral, prostatic cancer and diabetes, among many others. Medical cases presentations were done by medical doctors with different specialties and cellular biologists, physics, mathematics and engineering PhD's. The central idea was that even the medical doctors knew about the sicknesses symptoms and characteristics, they not always have the instruments or equipment required for diagnostics and treatment; on the other side the researchers in areas related to physics and mathematics know about physical principles as the cells electrochemistry, the response of cells or soft tissue to ultrasound, photonics or microwaves, etc; but not always have access to patients to test and experiment their measurement systems and theories.

After two years, some collaboration projects resulting from the seminaries were profiled, leading to high level negotiations to determine the best way to perform all of them. In the discussions participated the general directors, the R\&D directors and the General Attorney representatives from both organizations. The negotiation of terms were done for some months leading to a general collaboration agreement signed by both parts, The Hospital General de México (HGM) and the CCADET. The HGM offered to the CCADET a physical space of about $100 \mathrm{~m}^{2}$ for the installation of a R\&D unit at the Hospital General de México. During the 
first quarter of 2013 all the installation works were done, including power outlets, lighting, clean air, furnishing and the installation of the experimental laboratory. The CCADET's HGM Research Unit was in full operation by the middle of 2013.

Lesson learned: the collaboration among institutions to carry on the development of new $\mathrm{R} \& \mathrm{D}$ units its very promising but requires the participation of a team of well trained personnel in Management of Technology and will require long time that could distract the attention from the new project development search. Some important R\&D results from this collaboration modality began a year later.

\subsection{Strange Behavior of Large Private Companies}

It is well known worldwide that because of their economic power, big firms of all over the world nearly always impose their conditions on negotiations. R\&D contract agreements are not the exception. A giant Mexican mining industrial firm (confidential name) in 2006 call the general director of the CCADET indicating their interest in the research results published about the synthesis of stable components of gold (Au) and silver (Ag) nanoparticles (Np) and their possible use in catalytic reformers. According with the UNAM's IP attorneys big companies always claim the total rights of the new knowledge resulting in the projects they finance, but are not willing to pay for them. But there is a problem, frequently the financing requested to perform the works of a collaboration agreement are just enough to pay the materials, some contracted human resources, scholarships, information; and so on, but it did not pay the technology value. In such a case a negotiation possibility is to share the IP property between the parts in some percentage, usually $50 \%$ for each. Once the results of the new project will be obtained, a technology valuation must be carried on in order the firm could pay the UNAM's IP percentage if they want to have the $100 \%$ of the patented knowledge value. In the case presented above, the collaboration agreement never was signed and it required the spent of long commercial and juridical negotiations time.

Lesson learned: a $\mathrm{R} \& \mathrm{D}$ public institution must present a clear proposal were the new development project financing requirements are separated from the value of the proprietary technology used as a base of the new investigation. Otherwise the proposal could be seen as a very high pricing quotation and never be signed because of the natural market prices regulation. The technology must be paid once the prototypes and the intellectual property titles have been obtained. The patenting cost could also be shared between the contracting parts.

\subsection{The New Applied Science and Technology Development Market}

With the purpose to support and foster the development of science and technology, and after a long time for planning, maturation and implementation, starting 2007 CONACYT launched a new financing program for the development of projects demanded by almost all the nation's economic sectors. The program was called the Sectorial Funds-CONACYT. The participating sectors were the Energy, Health, Economy (Trade), Social Development, Transport \& Communications, Marine and Airports and Auxiliary Services, among many others.

According with the project financing program administrative manual, the academic personnel is restricted to publish their new knowledge findings, they do not obtain any extra payment, nor 
the organization, the project development responsibility is very high and of course it is also necessary to accomplish with the project scope and deliverables on time. Technology developed prototypes must be functional and the social or economic governmental sector always claims the total intellectual property results property. It is also necessary to compete with other universities in order to obtain project development funds in this type of project calls which is a major effort while it seems to be just occupational therapy because the benefits other than helping to solve a problem through technological development are insignificant.

Lesson learned: several groups of the CCADET have submitted proposals for many project calls, but the benefits for the organization have been limited. The motivations the organization and the academic personnel have for participating in this kind of programs have been limited.

\subsection{Economy Secretary Innovation Funds}

A particular case of the CONACYT's Sectorial Funds is the issued for the Federal Economy Secretary. First call was in 2008 and its objective was to provide funds for financing the R\&D projects requested for private firms in order to develop new technological products to make them more competitive. In this case half of the funds came from the same Economy Secretary, and half from CONACYT. Likewise, the reference terms asked for concurrent funds to the bidding enterprises. Depending on the size of the firm and the money amount requested the program establishes three different categories. INNOVAPYME are directed for small and medium enterprises, FINNOVA for big enterprises and INNOVATION Networks for clusters of big, medium and small enterprises including public and private R\&D groups from universities.

Lessons learned: Working in conjunction with many different firms of all sizes, the center had presented at least 30 different techno- economic proposals and in five years just obtained five collaboration agreements. Once again, the efficiency is very low if we take in account the time of the academic and administrative human resources used to prepare and present the proposals and the incredible short time required by the conveners to participate.

\subsection{Petroleos Mexicanos-CONACYT Hydrocarbon Energy Sectorial Funds}

In 2011 a private national firm invited the academic group of modeling and simulation processes of the CCADET to participate submitting a common proposal for the Hidrocarbon Energy Sectorial Funds. The specific objective was to install, build and use the necessary instrumentation to detect the hydrocarbon gases produced by the oil storage tanks installed at the production wells. The hypotheses behind was that the continuous liberation of the gases produced in the thousands of tanks installed in the different production fields existing in all the country must seriously impact the environment and the air quality. There were more than two hundred man-hours spent by the technical groups of the firm and the academic and directive personnel of the CCADET with the staff of CONACYT. There were also many meetings for technical issues, proposal strategy definition and negotiations. The online proposal was presented in December 2011, with the promise of having the decision in a term of 60 days. The results of the call appeared at CONACYT's Internet page by the middle of 2012 but the results for the specific demand in which we bid never appeared, there was just a note in the bottom of 
the page stating that some proposals were still in evaluation by the responsible committee and that more results would be published later. More than eight months later results neither appeared nor a clarifying advice. We never receive a message from the responsible of the Fund at CONACYT.

Lesson learned: the time spent in the phase one of the Management of Technology model sometimes never ends. The academic and administrative participants can not report the expended time, academics have trouble with their year results report. The center spent time, money and efforts and sometimes the organizers does not have the courtesy to advise that the evaluation process has ended, probably because they have a lot of work.

\section{Future of the L \& MoT}

The future of the CCADET's L \& MoT will depend on the knowledge management strategies that the center will follow. Today center efforts are directed to increase the internal research and infrastructure capacities and a new National laboratory of Aditive Manufacturing, Digitalización 3D digitalization and Computarized Tomography (MADiT) and a Modern Spectroscopy University Laboratory. This new laboratories will enhance the Center's capacities to offer more and better services to the university community and to external organizations and firms. Many of the academic R\&D groups are developing health related projects. Furthermore, negotiations are on the way to establish a new R\&D Units at the Hospital Manuel Gea González and probably at other important hospitals and Health Research Institutes at the future.

To have an efficient and long term relation, an important issue to be considered for the new strategy technological alliances between the CCADET and the General Hospitals of the Federal Health Secretary, is the alliance stability connotations discussed by Zhang-sheng et al. (2008), specifically in regard to the alliance goals, contracts, operations controls modes and annexation. This is a new working field for the L \& MoT since the center researchers and academic personnel shall learn how to interact and communicate with the hospital's R\&D medical researchers in order to develop a common language for the decision making process. We are in the way of performing Trans-disciplinary projects with social impact.

Bozeman (2000), mentions that the Committee on Science and Technology of the US Congress, stated that in general, in the USA the process of commercializing intellectual property is very complex, highly risky, takes a long time, cost much more than the projected, and usually fails. Of course in Mexico the situation of the university technology transfer to external private firms is very similar, nevertheless the L \& MoT CCADET's office must continue with strong efforts in the field of Intellectual Property works, pursuing applications for more patents, industrial models, copyrights and software rights. Technology Transfer for the patented technologies will be also pursued. Some interest and opportunities for TT have been recognized. The L \& MoT personnel will probably be increased and the search for external financed projects will continue. Llor (2007) proposed that the basic indicators for the whole innovation process in a country are counts of annual patents filings, annual patent grants, annual licensing agreements, active patents and licenses (portfolio), and annual licensing revenues. Nevertheless, the results of the center in both technology development and 
Intellectual Property have a small stake in the university innovation efforts.

Today the L \& MoT CCADET's Office is backing up the center's efforts in innovation projects $(\mathrm{R} \& \mathrm{D}+\mathrm{I})$. It interfaces with the external firms, understanding the business language and motivations and at the same time interfaces with the UNAM's diverse attorney's offices trying to understand the Mexican and international laws and the legal language of them. Finally it interfaces the internal academic personnel with the firms and the government project financing agencies. In the next ten years the CCADET will continue maturing as a R\&D organization and we expect that new whole integrated devices and prototypes for medical diagnostics, nanotechnology and renewal energy systems specific applications and laboratory analyzers will be available. The required IP certificates and patent applications must be filed and once the patent titles be obtained very interesting technology transfer negotiations are expected to come. For the time being, the non-standard lessons learned during the L \& MoT operation years could be advisable for other professionals working in technology management in the third development countries.

\section{Conclusions}

For 15 years the L \& MoT CCADET's office has been acting as the center's project administration and linking and external relations office. With the creation of an intellectual property unit it has been doing steps to be converted into a TTO.

The limited standard results shown in the graphics of the previous sections, show that apparently research fellows are more interested in performing their own basic research projects and experiments whose results can be disseminated and published than participating in technological development projects required and financed by external organizations. This happens even when University regulations permit the payment of extraordinary incomes to the participants in those kind of projects, therefore we have empirical evidence to think that it is mandatory to improve the innovativeness of the CCADET's academic personnel because empirical studies have shown that organizational trust, knowledge transfer, knowledge creation, and innovativeness are related to each other. (Sankouska, 2013)

The standard results also show that approximately $90 \%$ of the external organizations that collaborate with the center are public and about a $10 \%$ are private firms; also just about a 7-8\% of the technical and commercial proposals presented to private micro and small firms are accepted and normally require the concurrence of governmental financing. Apparently there is a lack of confidence in the private sector to get linked with the University to develop the science and technology they require. It seems to be a cultural problem aggravated by the scarce economic resources.

An interesting and paradoxically situation is the confidence of international firms to collaborate with the Center. The CCADET has developed several technology projects via direct financing for international firms. Its researchers have also received scientific research grants from diverse international corporations who normally demand the intellectual property of knowledge results. This is the kind of situations that requires appropriate negotiation terms generated at the L \& MoT. 
Besides of the administrative paper work for filing the applications, the Intellectual Property Unit of the L \& MoT is in charge of managing the Center's intellectual property strategy through discussions with the academic inventors, the institution officials and the director. Therefore, the development of this strategy is a real management challenge (Slowinski \& Zerby, 2008).

On the other hand, in the last 20 years the promotion of the entrepreneurship has emerged as a new role for the universities (Landry et al., 2006). The UNAM is doing efforts in this direction and regulations for new spin off knowledge based university firms are on the way. This new area probably will also be under the L \& MoT responsibilities.

Wen-Hsiang, \& Chien-Tzu, (2008) found that the technological level found in high tech industries fosters technology transfer. Nevertheless in Mexico more than $98 \%$ of the firms in the country are micro, small and medium, and just a small fraction of them are hi-tech. This situation will probably be the most influential factor for the technology transfer effectiveness,

Regarding the licensing annual incomes, the best year the center received royalties for about $7 \%$ of its total expenditure in research but the average year incomes coming from licencees are below $2 \%$, percentage which is too low compared on what occurred at the USA universities (Swamidass \& Venubabu. 2009).

In its operation life, the CCADET's L \& MoT office has overcome many barriers in order to obtain meaningful results. The non-standard results of the failed negotiations have taught us that many difficulties for technology transfer come from the very early negotiation stages so that it is required a lot of team work to obtain meaningful results. The time required for the activities of linking and negotiation conducted during phase I of the MoT model usually takes longer than the time required for the legal agreements \& project administration performed in phase II. Notably, it is necessary to present more than a dozen of proposals with different degree of complexity, to get a project contract signed. So the distinctive features of the L \& MoT office must be the negotiating capacity and the patience in order to build its reputation (Macho-Stadler et al., 2007).

\section{References}

Amin, A., \& Cohendet, P. (2004). Architectures of knowledge: Firms, capabilities and communities. Oxford: Oxford University Press. http://dx.doi.org/10.1093/acprof:oso/9780199253326.001.0001

Arora, A., Fosfuri, A., \& Gambardella, A. (2001). Markets for Technology: the Economics of Innovation and Corporate Strategy. Cambridge, MA: MIT Press.

Bart, C., Wright, M., Lockett, A., Mustar, P., \& Knockaert, M. (2007). Academic spin-offs, formal technology transfer and capital raising. Industrial and Corporate Change, 16(4), 609-640. http://dx.doi.org/10.1093/icc/dtm019

Bozeman, B. (2000). Technology transfer and public policy: a review of research and theory. Research Policy, 29, 627-655. http://dx.doi.org/10.1016/S0048-7333(99)00093-1 


\section{Macrothink}

Case Studies in Business and Management ISSN 2333-3324 2016, Vol. 3, No. 1

Bradley, R. S., Hayter, S. C., \& Link, N. A. (2013). Models and Methods of University Technology Transfer. Department of Economics Working Paper Series, Working Paper 13-10. http://dx.doi.org/10.1007/s10961-013-9309-8

CCADET (2014). Centro de Ciencias Aplicadas y Desarrollo Tecnológico. [Online] Available: http://www.ccadet.unam.mx

Chagoya, H. (2012). Technology transfer offices: a boost to licensing in Mexico. Becerril, Coca \& Becerril. [Online] Available: http://www.lexology.com/library/detail.aspx?g=761ffe6c-a5d2-4faf-a358-86f93fe940c8

Cohen, W. M., Florida, R., Randazzese L., \& Walsh, J. (1998). Industry and the Academy: Uneasy Partners in the Cause of Technological Advance, in Challenges to Research Universities. Washington, D.C.: Brookings Institution Press.

CONACYT (2014). Consejo Nacional de Ciencia y Tecnología. [Online] Available: http://www.conacyt.gob.mx

Connelly, M. C., Dismukes, J. P., \& Sekhar, J. A., (2009). New Relationships between Patents and Technological Innovation: Modeling Patent Activity as a Driver of Innovation. In papers presented at PICMET 2009 Proceedings, Portland, Oregon USA.

Davenport, T., Jarvenpaa, S., \& Beers, M. (1996). Improving knowledge work processes. Sloan Management Review, 37(4), 53-66.

Franzoni, C. (2007). Opportunity recognition in technology transfer organizations: Five case studies from UK and Italy. International Entrepreneur Management Journal, 3, 51-67. http://dx.doi.org/10.1007/s11365-006-0014-z

Grant, R. M. (1996). Toward a knowledge-based theory of the firm. Strategic Management Journal, 17(Special Issue), 109-122. http://dx.doi.org/10.1002/smj.4250171110

Hockaday, T. (2009). Building a Technology Transfer Office - Starting Out. University of Oxford.

[Online]

Available:

http://www.isis-innovation.com/news/articles/buildingatto.html

Landry, R., Amara, N., \& Mathieu, M. M. (2006). Determinants of knowledge transfer: evidence from Canadian university researchers in natural sciences and engineering. $J$. Technol Transfer, 32, 561-592. http://dx.doi.org/10.1007/s10961-006-0017-5

Llor, A. (2007). Delay from patent filing to technology transfer: A statistical study at a major public research organization. Technovation, 27, 446-460. http://dx.doi.org/10.1016/j.technovation.2006.10.002

Macho-Stadler, I., Pérez-Castrillo, D., \& Veugelers, R. (2007). Licensing of university inventions: The role of a technology transfer office. Int. Journal of Industrial Organization, 25, 483-510. http://dx.doi.org/10.1016/j.ijindorg.2006.06.001

OECD (2003). Turning Science into Business, Patenting and Licensing at Public Research Organizations. OECD Paris. 


\section{Macrothink}

Case Studies in Business and Management

ISSN 2333-3324

2016, Vol. 3, No. 1

Pluvia, Z. M., Dominique, G. (2009). Who Licenses Out Patents and Why? Lessons from a Business Survey. Statistical Analysis of Science, Technology and Industry. Working Paper No. DSTI/DOC(2009)5. Organization for Economic Co-operation and Development,

Rosenberg, N., \& Nelson, R. R. (1994). American universities and technical advance in industry. Research Policy, 23, 323-348. http://dx.doi.org/10.1016/0048-7333(94)90042-6

Saniger, B. J. (2013). CCADET Development Plan 2009-2012. [Online] Available: http://www.ccadet.unam.mx

Sankouska, A. (2013). Relationships between organizational trust, knowledge transfer, knowledge creation, and firm's innovativeness. Learning Organization, 20(1), 85-100. http://dx.doi.org/10.1108/09696471311288546

Siegel, D. S., Waldman, D., \& Link, A. N. (2003). Assessing the impact of organizational practices on the relative productivity of university technology transfer offices: an $\begin{array}{lllll}\text { exploratory study. } & \text { Research }\end{array}$ http://dx.doi.org/10.1016/S0048-7333(01)00196-2

Slowinski, G., \& Zerby, K. W. (2008). Protecting IP in collaborative research. Research Technology Management, 51(6), 58-65.

Swamidass, P. M., \& Venubabu, V. V. (2009). Why university inventions rarely produce income? Bottlenecks in university technology transfer. J. Technology Transfer, 34, 343-363. http://dx.doi.org/10.1007/s10961-008-9097-8

Vega-González, L. R., Nairn, J., Stiles, B., \& Ascanio, G. G. (2012). International private-public collaboration for technology development and knowledge generation: the development of an automatic molding press. Int. J. Technology Intelligence and Planning, 8(3), 278-294. http://dx.doi.org/10.1504/IJTIP.2012.048574

Wen-Hsiang, L., \& Chien-Tzu, T. (2008). Analyzing Influence Factors of Technology Transfer Using Fuzzy Set Theory. Papers presented at PICMET 2008 Proceedings, Cape Town, South Africa. http://dx.doi.org/10.1109/picmet.2008.4599852

Zhang-sheng, J., Long-ying, H., \& Ye-zhuan, T. (2008). Research on stability of industrial technological innovation strategic alliance based on knowledge transfer. International Conference on Management Science \& Engineering (15th, pp. 1509-1515). IEEE, USA.

Zhao, L., \& Reisman, A. (1992). Toward Meta Research on Technology Transfer. IEEE Transaction on Engineering Management, 39(1), 13-21. http://dx.doi.org/10.1109/17.119659 


\section{Copyright Disclaimer}

2016, Vol. 3, No. 1

Copyright for this article is retained by the author(s), with first publication rights granted to the journal.

This is an open-access article distributed under the terms and conditions of the Creative Commons Attribution license (http://creativecommons.org/licenses/by/3.0/). 